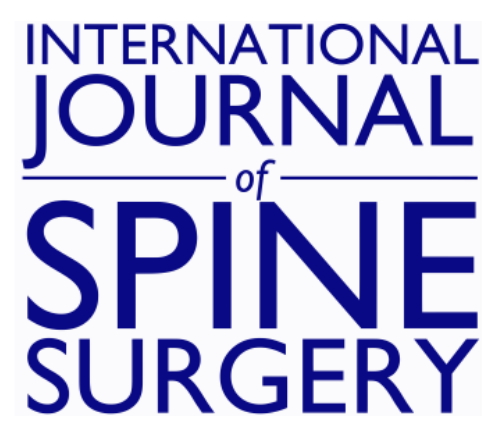

\title{
Simplified Pedicle Subtraction Osteotomy for Osteoporotic Vertebral Fractures
}

Nicolas Plais, Charles-Louis Raphael Mengis, Jesús Manuel Gallego Bustos, Felix Tomé-Bermejo, Alejandro Peiro-Garcia, America Novoa Buitrago and Luis Alvarez Galovich

Int J Spine Surg published online 22 September 2021

http://ijssurgery.com/content/early/2021/09/20/8129

This information is current as of April 26, 2023.

Email Alerts Receive free email-alerts when new articles cite this article. Sign up at:

http://ijssurgery.com/alerts

The International Journal of Spine Surgery

2397 Waterbury Circle, Suite 1,

Aurora, IL 60504, Phone: +1-630-375-1432 


\title{
Simplified Pedicle Subtraction Osteotomy for Osteoporotic Vertebral Fractures
}

\author{
NICOLAS PLAIS, MD, ${ }^{1}$ CHARLES-LOUIS RAPHAEL MENGIS, MD ${ }^{2}$ JESÚS MANUEL GALLEGO \\ BUSTOS, MD ${ }^{2}$ FELIX TOMÉ-BERMEJO, $\mathrm{MD}^{3}$, ALEJANDRO PEIRO-GARCIA, MD ${ }^{4}$ AMERICA NOVOA \\ BUITRAGO, MD,${ }^{1}$ LUIS ALVAREZ GALOVICH MD ${ }^{2}$ \\ ${ }^{1}$ Hospital Universitario San Cecilio de Granada, Granada, Spain, ${ }^{2}$ Hospital Universitario Fundación Jiménez Diaz, Madrid, Spain, ${ }^{3}$ Hospital Universitario General \\ de Villalba, Madrid, Spain, ${ }^{4}$ Hospital Sant Joan de Déu Barcelona, Barcelona, Spain
}

\begin{abstract}
Background: In osteoporotic vertebral fractures (OVF) involving neurological symptoms and severe kyphosis, vertebral osteotomies are necessary but are associated with a high risk of complications.

Methods: We performed a retrospective study. In 14 patients (mean age, 69.3 years old) with unstable thoracolumbar fractures associated with severe kyphosis, a posterior instrumentation with polymethylmethacrylateaugmented screws and a modified pedicle subtraction osteotomy (PSO) at the fracture level were performed to stabilize the spine and correct the kyphosis. The underlying principle behind the osteotomy's technique was to exaggerate the defect caused by the fracture and shorten the spine: (1) completion of a wide laminoforaminotomy, (2) use of successive reamers rotated in the pedicle at a $25^{\circ}$ angle in the axial plane to obtain its complete decancellation, (3) insertion of the reamers in a more medial orientation $\left(55^{\circ}\right)$ to collapse the posterior wall, and (4) breakage of the lateral wall. Radiographic and clinical outcomes were analyzed pre- and postoperatively. Complications were reported.

Results: Functional scores improved after surgery. Oswestry disability index and visual analog scale scores decreased significantly (33 and 4 points, respectively). Patient satisfaction rate reached 93\%. Average postoperative regional vertebral kyphosis was decreased to $3.79^{\circ}$. No dural tear or neurological injuries were observed. Blood loss of $920 \mathrm{~mL}( \pm 350 \mathrm{~mL})$ and two mechanical complications were reported.

Conclusions: OVF can lead to severe deformities. In osteoporotic bones, the use of sequential reamers can simplify the PSO technique, allowing for the shortening and stabilization of the spine without manipulating the dural sac. The risk of neurological injuries and blood loss is decreased.
\end{abstract}

Level of Evidence: 4.

Minimally Invasive Surgery

Keywords: pedicle subtraction osteotomy, decancellation technique, osteoporotic vertebral fractures, kyphosis, spine trauma, osteoporosis, spinal instability, complications

\section{INTRODUCTION}

The treatment of osteoporotic vertebral fractures (OVF) represents a formidable challenge for societies, health systems, and spine surgeons. In aging populations, the incidence of OVF has risen up to 1.4 million a year. ${ }^{1}$ At least $50 \%$ of the osteoporotic fractures that occur in the United States are vertebral fractures. ${ }^{2}$ Forty percent of patients older than 80 years will suffer from an OVF. ${ }^{3}$

Although the majority of OVFs are relatively benign and can be treated conservatively, 30 to $40 \%$ of the fractures present complications ${ }^{4}$ that can require surgical treatment. The presence of neurological symptoms, instability at the fracture site causing delayed neurological deficits, significant radiological spinal canal compromise, instability at the disc-vertebral junction, posttraumatic kyphosis, and intractable pain that is not alleviated by conservative treatments have been described as indications for surgery. ${ }^{5-9}$

A wide variety of techniques and approaches have been described to stabilize the spine, decompress the spinal neural elements when necessary, and alleviate pain, including postero-lateral, ${ }^{7,10,11}$ anterior-posterior, ${ }^{6,12}$ hybrid surgery, ${ }^{7,13}$ etc. In specific and complex cases involving severe kyphosis (more than $30^{\circ}$ ) and/or sagittal malalignment, vertebral osteotomies have been recommended. ${ }^{14}$ These techniques have a high potential of correction of malalignment but are technically demanding and subject to high risk of complications. OVFs frequently occur in older patients who present 
Table 1. Demographic data.

\begin{tabular}{lclccccc}
\hline $\begin{array}{l}\text { Patient } \\
\text { no. }\end{array}$ & Age & Gender & $\begin{array}{c}\text { T-score } \\
\text { Hip }\end{array}$ & $\begin{array}{c}\text { T-score } \\
\text { Vertebral }\end{array}$ & $\begin{array}{c}\text { Charlson } \\
\text { Morbidity } \\
\text { Index, \% }\end{array}$ & $\begin{array}{c}\text { ASA } \\
\text { Score }\end{array}$ & BMI \\
\hline 1 & 67 & Female & -2.4 & -2.3 & 90 & 3 & 26.6 \\
2 & 76 & Female & -3.5 & -1.6 & 77 & 2 & 31.6 \\
3 & 77 & Female & -2.7 & -2.7 & 53 & 3 & 32.3 \\
4 & 64 & Female & -3.3 & -3.4 & 53 & 3 & 28.8 \\
5 & 82 & Female & -3.4 & -3.8 & 30 & 2 & 25.4 \\
6 & 71 & Female & -3.4 & -4.2 & 90 & 3 & 15.6 \\
7 & 69 & Female & -3.2 & -2.1 & 26 & 2 & 26.5 \\
8 & 55 & Female & -3 & -2 & 52 & 3 & 32.0 \\
9 & 66 & Male & -2.3 & -1.9 & 21 & 3 & 25.0 \\
10 & 79 & Female & -3.5 & -4.8 & 96 & 2 & 20.6 \\
11 & 75 & Female & -4.3 & -3.5 & 53 & 2 & 34.7 \\
12 & 74 & Female & -3 & -2.1 & 26 & 2 & 28.9 \\
13 & 78 & Female & -3.2 & -3.6 & 85 & 3 & 36.4 \\
14 & 38 & Female & -3.9 & -5.2 & 90 & 3 & 17.5 \\
\hline
\end{tabular}

Abbreviations: ASA, American Society of Anesthesiologists; BMI, body mass index.

important comorbidities. In these frail patients, long surgeries combining anterior and posterior approaches are not well supported.

The objective of this study is to present some technical variations of classical pedicle subtraction osteotomies to take advantage of the specific characteristics of the osteoporotic bone and simplify the technique of the osteotomy to make the surgery less invasive and decrease the risk of neurological injuries to the spinal cord.

\section{METHODS}

\section{Patient Population}

Between 2008 and 2018, we enrolled 14 patients with unstable fractures associated with thoracolumbar kyphosis or sagittal malalignment. The patients included 13 females and 1 male with a mean age of 69.3 years at the moment of surgery. All the patients presented severe osteoporosis assessed by densitometry. Body mass index, Charlson comorbidity index, and American Society of Anesthesiologists scores were obtained for all the patients before surgery (Table 1).

The mechanism of action excluded high energy trauma, and the fractures were related to stress or low energy falls. The presence of neurological deficits was identified in 5 patients. Two patients were graded $\mathrm{C}$, and three other patients were graded $\mathrm{D}$ on the American Spinal Injury Association impairment scale. The vertebral fractures affected the thoracolumbar junction in almost all the cases (7 were identified at L1, 5 at T12, 1 at T10 and T11, and 1 at L3). Average kyphosis at the fractured level was $29.4^{\circ}$ (Table 2 ).

\begin{tabular}{|c|c|c|c|c|}
\hline $\begin{array}{l}\text { Patient } \\
\text { no. }\end{array}$ & $\begin{array}{l}\text { Level of the } \\
\text { Fracture }\end{array}$ & Preop VK & Preop RK & ASIA Scale \\
\hline 1 & L3 & 29 & 34 & $\mathrm{D}$ \\
\hline 2 & $\mathrm{~T} 11$ & 40 & 53 & $\mathrm{E}$ \\
\hline 3 & $\mathrm{~T} 12$ & 25 & 47 & $\mathrm{C}$ \\
\hline 4 & L1 & 21 & 31 & $\mathrm{E}$ \\
\hline 5 & $\mathrm{~L} 1$ & 13 & 26 & $\mathrm{E}$ \\
\hline 6 & $\mathrm{~T} 12$ & 33 & 45 & $\mathrm{E}$ \\
\hline 7 & $\mathrm{~T} 12$ & 28 & 30 & $\mathrm{E}$ \\
\hline 8 & $\mathrm{~L} 1$ & 26 & 33 & $\mathrm{E}$ \\
\hline 9 & $\mathrm{~T} 12$ & 45 & 47 & $\mathrm{D}$ \\
\hline 10 & $\mathrm{~T} 11$ & 31 & 49 & $\mathrm{E}$ \\
\hline 11 & $\mathrm{~L} 1$ & 41 & 45 & $\mathrm{D}$ \\
\hline 12 & $\mathrm{~L} 1$ & 29 & 38 & $\mathrm{E}$ \\
\hline 13 & $\mathrm{~L} 1$ & 15 & 17 & $\mathrm{C}$ \\
\hline 14 & $\mathrm{~T} 12$ & 36 & 43 & $\mathrm{E}$ \\
\hline
\end{tabular}

Abbreviations: ASIA, American Spinal Injury Association; Preop RK, preoperative regional kyphosis; Preop VK, preoperative vertebral kyphosis.

In the absence of neurological deficits, all the patients were initially treated with a row of conservative treatment with brace, pain killers, and rest. The presence of neurological symptoms or severe kyphosis associated with persistence of intractable pain despite treatment were the main arguments for surgery. The study was performed with the approval of the ethics committee under the project number EO62/2016.

\section{Clinical and Radiological Outcomes}

Radiographic parameters were measured with validated software (Surgimap). To analyze the correction of kyphosis obtained during the surgery and its maintenance after 2 years, regional kyphosis and vertebral kyphosis were measured preoperatively, postoperatively, and at final follow-up (2 years). Regional kyphosis was defined as the Cobb angle between the inferior platform of the adjacent vertebra below the fractured vertebra and the superior platform of the adjacent vertebra above the fractured vertebra, and vertebral kyphosis was defined as the Cobb angle between the upper and the lower platform of the fractured vertebra (Figure 1). Functional improvement was assessed thanks to standardized health-related quality of life questionnaires, including pre- and postoperative Oswestry disability index (ODI) and visual analog scale (VAS) for back and leg pain.

Mean operation time and intraoperative blood loss were assessed. Intraoperative, early, and late complications were cautiously reported. Mechanical complications, such as loss of correction, instrument failure, screw loosening, and proximal or distal junctional kyphosis were specially monitored. 


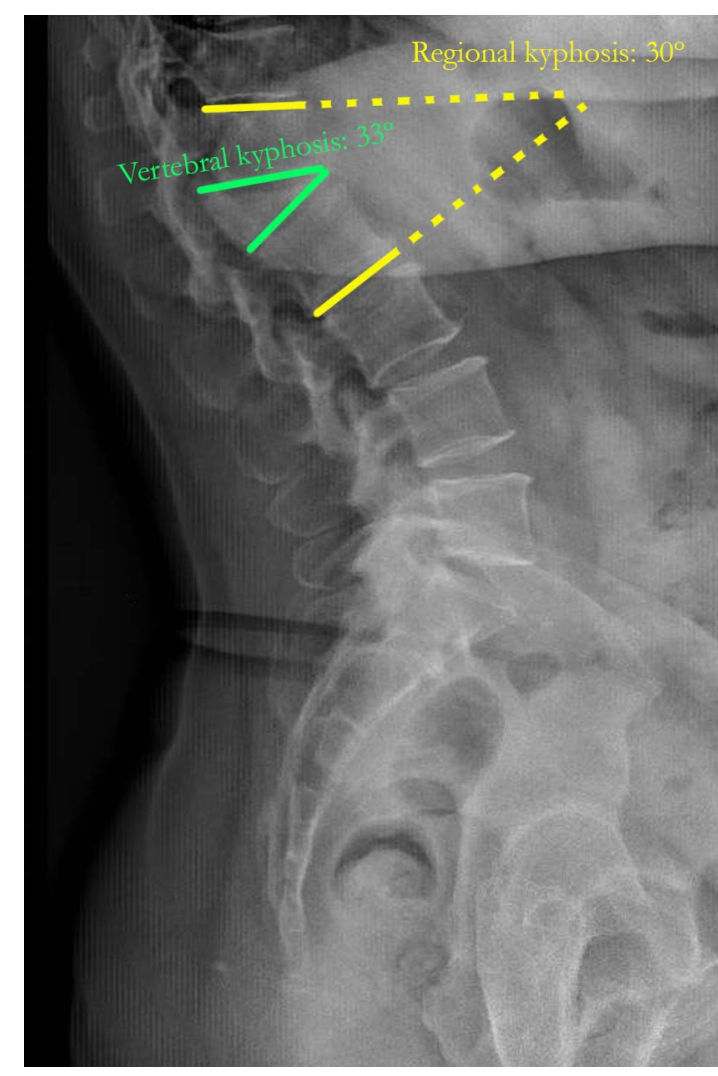

Figure 1. Regional and vertebral kyphosis.

\section{Description of the Technique}

\section{Patient Preparation}

After proper identification of the patients and prior informed consent, patients were taken to the operating room. General anesthesia and preoperative antibiotics were administered as per anesthesia protocol. The patients were then placed in a prone position on a four-poster frame. All weight-bearing surfaces were carefully padded. Neuromonitorization with somatosensory and motor evoked potentials was performed for all procedures. Once sterile preparation and drape of the thoracic and lumbar region were performed, timeout was completed.

\section{Osteotomy}

Approach. A posterior incision was made at the level of the fractured vertebra followed by dissection down to the fascia, which was spit midline. A subperiosteal dissection was carried out to the bony elements of the spine. The laminas of fractured vertebra and the upper and lower adjacent vertebras as well as the starting points for the pedicle screws above and below the osteotomy were exposed. In general, a construct planned with two levels above and below was enough.

Fixation and Decompression. To give time for the polymerization to occur and to avoid loosening of the screws, ${ }^{15}$ we began with the insertion of polimethylmethacrylate-augmented pedicle screws at the upper and lower adjacent vertebrae. Freehand pedicle screw insertion was used for all cases. Once inserted, cement injection was controlled by fluoroscopy with the $\mathrm{C}$-arm in lateral projection. All the fenestrated screws were injected with a mean of 3 $\mathrm{mL}$ of cement per screw in the lumbar spine and 2.5 $\mathrm{mL}$ for thoracic screws. A stepwise injection technique was followed to monitor closely cement flow in real time. If cement leakage was observed, the injection was stopped immediately.

Then, a wide laminoforaminotomy at the fractured level was performed to decompress the spine. The decompression was extended up to the distal lamina of the lower vertebra and proximal lamina of the upper vertebra. Once the laminoforaminotomy was completed, the pedicles of the fractured vertebrae were circumscribed bilaterally. The exiting roots above and below the pedicle were identified on both sides and protected during the procedure.

Osteotomy. The first step of the osteotomy begins by inserting a spike in each pedicle to clearly identify its limits. Then, successive reamers similar to those used to prepare the disk in transforaminal lumbar interbody fusion are placed and rotated in the pedicle with 20 to $25^{\circ}$ of angulation in the axial plane. This gesture is safe as the dural sac is protected by the medial wall of the pedicle. Reamers from $7 \mathrm{~mm}$ to $11 \mathrm{~mm}$ are placed until a complete decancellation of the pedicle is obtained (Figure 2).

At this point, for the second step of the osteotomy, the reamers were inserted again but this time in a much more medial orientation to fragilize the posterior wall $\left(55-60^{\circ}\right.$ of angulation in the axial plane). The osteoporotic bone is easily removed with each rotation of the reamer, and, once realized bilaterally, the posterior wall collapses. As the objective is to collapse the posterior wall, there is no need to deepen the reamers more than $25 \mathrm{~mm}$. During this step, the dural sac was protected all the time by the posterior longitudinal ligament that will not be removed. Temporal stabilizing rods can be 


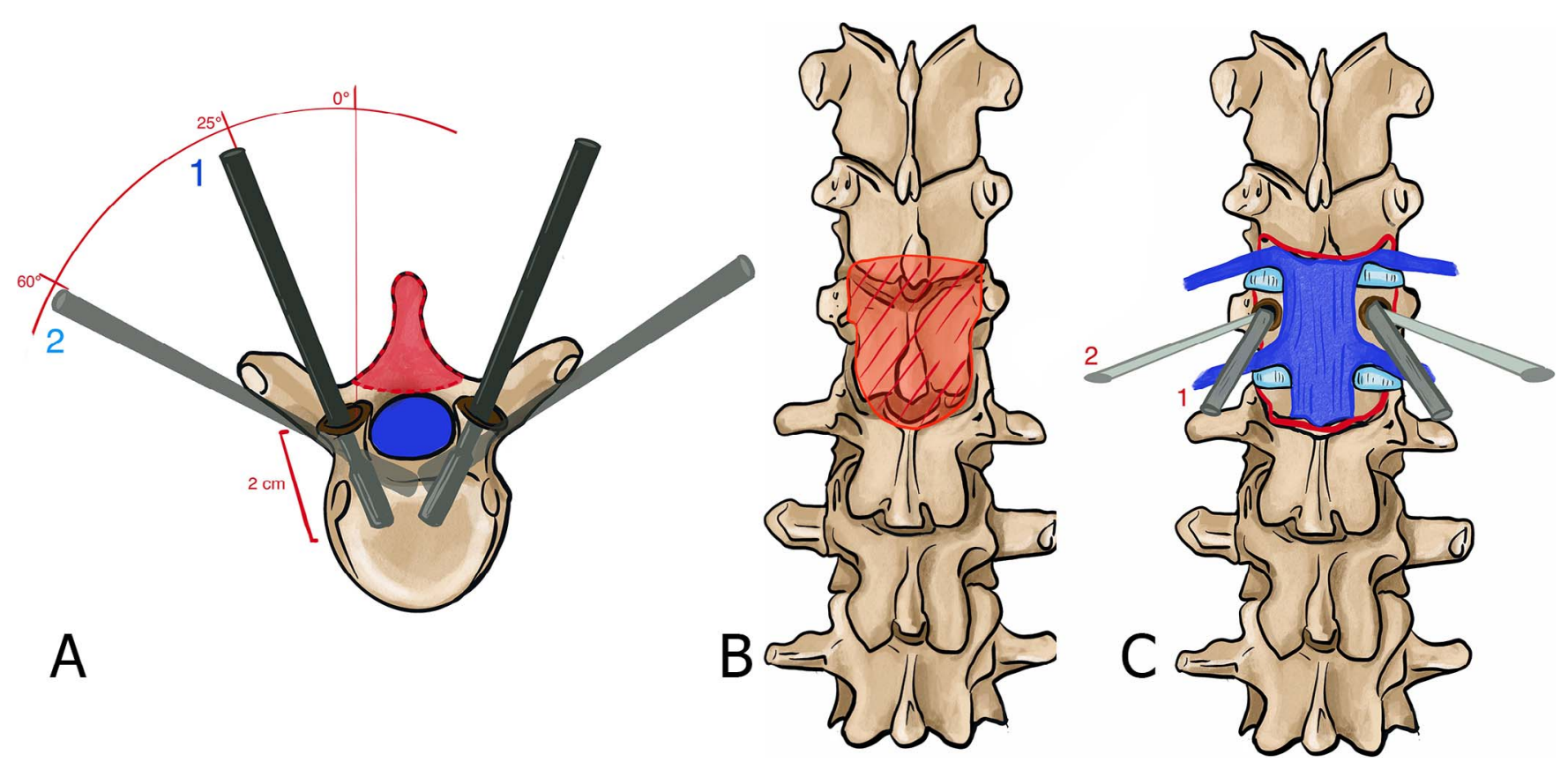

Figure 2. Description of the technique. (A) Axial view of the insertion of the reamers. (B) Decompression with a wide laminoforaminotomy of the fractured level (anterior posterior view). (C) Anterior posterior view of the insertion of the reamers (step 1: $25^{\circ}$ of angulation in the axial plane; step 2: $55^{\circ}$ of angulation in the axial plane).

placed at this point; however, as the lateral wall is still intact, this is not absolutely necessary. The last step of the osteotomy is the breakage of the lateral walls, which is performed with an osteotome at each side. The osteotome must not be deepened more than $25 \mathrm{~mm}$. Finally, the osteotomy is closed gently with slight compression (Figure 3). Auto and allografts were placed in the posterior spine.

Length of the Construct. Two different techniques have been used. In our first cases, the objective was to instrument as short as possible, taking advantage of the greater purchase of expanded screws to create short constructs (Figure 4). To decrease the risk of proximal (PJK) or distal junctional kyphosis, the technique evolved to longer instrumentations using minimally invasive techniques. For these cases, percutaneous incisions were made for the placement of the upper and lower end of the instrumentation. Once the fascia was open, 8 fenestrated screws were inserted percutaneously. Each screw was expanded with 2 to $4 \mathrm{~mL}$ of polymethylmethacrylate cement under continuous image intensifier visualization,
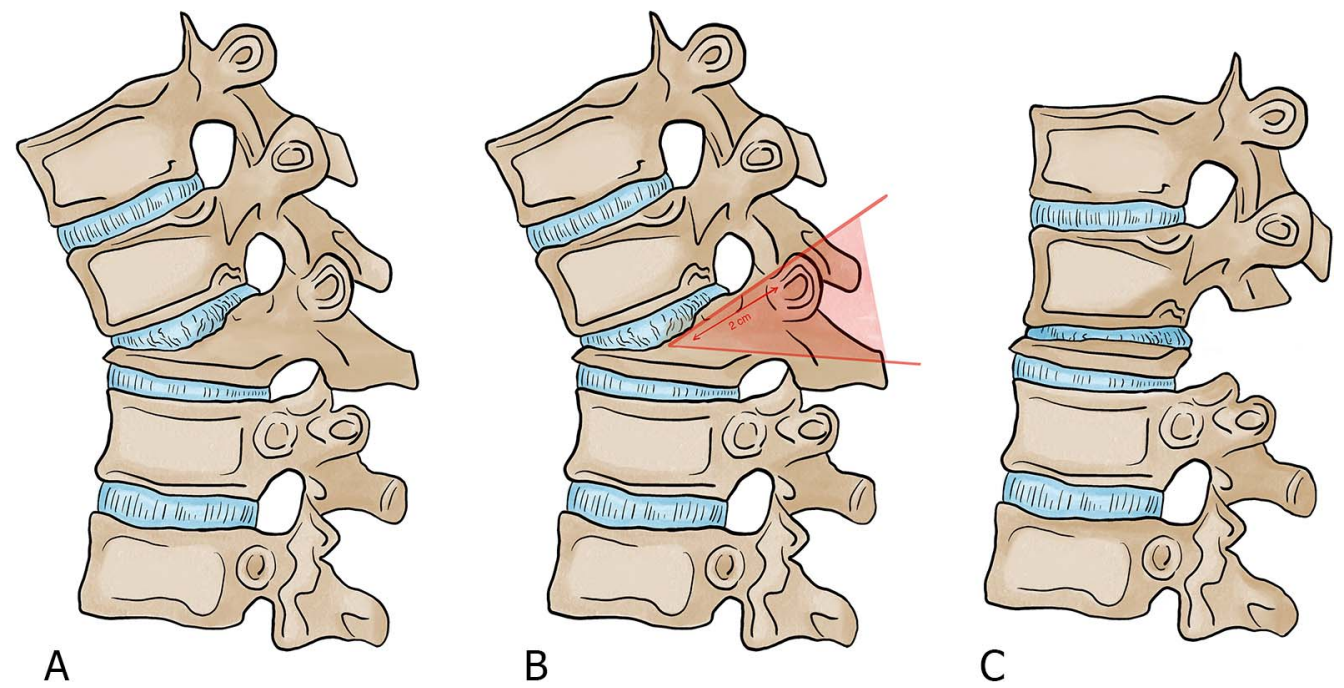

Figure 3. Description of the osteotomy in the sagittal plane. (A) Kyphosis caused by the fracture. (B) Planification of the osteotomy. (C) Closure of the osteotomy. 


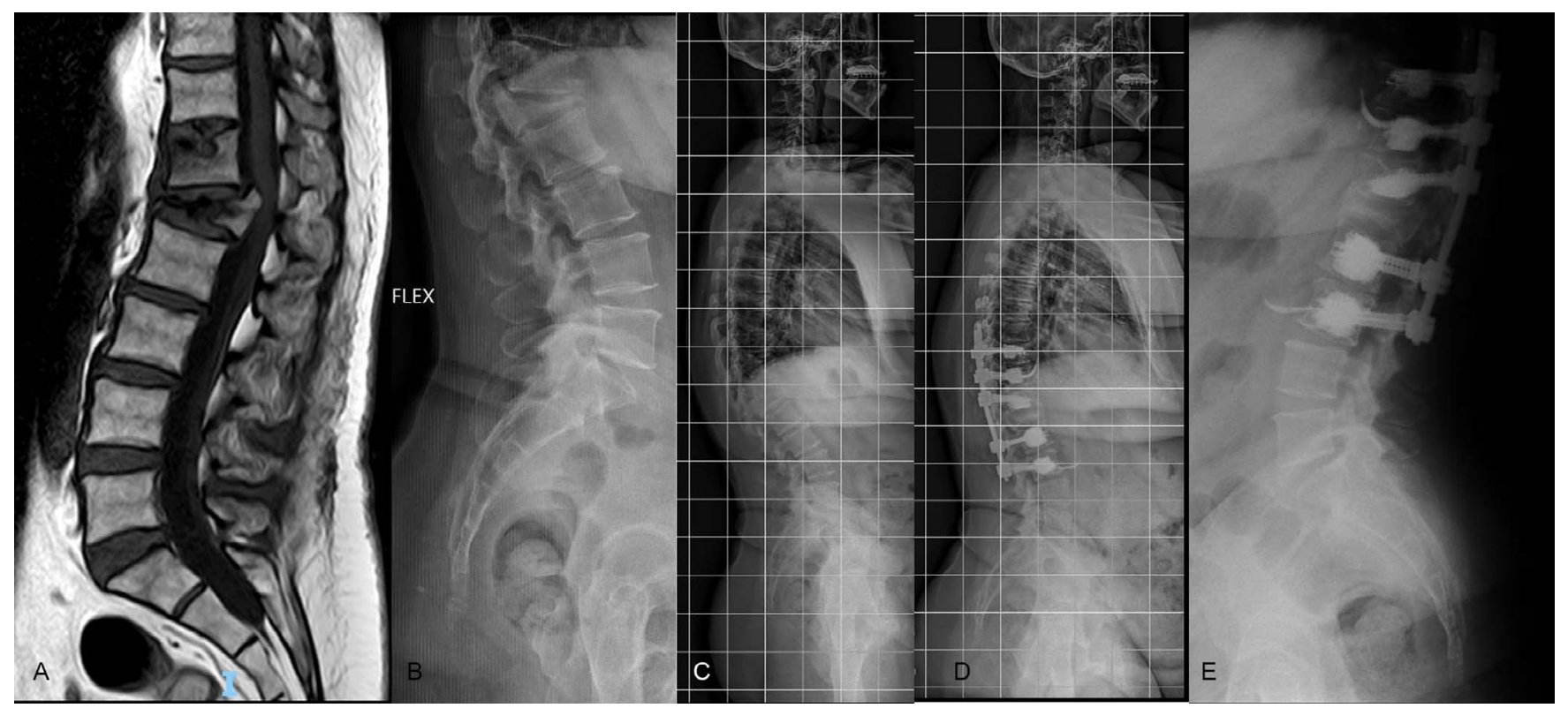

Figure 4. L1 osteotomy, open technique.

depending on the level (thoracic or lumbar). A subcutaneous rod was then inserted from top to bottom under the fascia. The distal screws were locked first. The compression was done between the screws of T10 and T12. The collapse of the posterior wall allows a compression of the fracture and an excellent correction of the local kyphosis. The upper screws were finally locked. The fascia and skin were closed (Figures 5 and 6).

Postoperative Care. To decrease pain and improve comfort, the use of a brace in standing position is recommended during 2 months to all the patients. If no contraindication is observed, treatment with teriparatide (PTH 1-34) is applied for 2 years as a secondary prevention to OVF.

\section{Statistical Analysis}

Measurements were performed using the picture archiving and communication system. For statistical analysis, SPSS (version 17.0, IBM) was used, and a $P$ value of $<.05$ was considered significant. To assess clinical and radiological differences pre- and postoperatively, paired $t$ tests were performed.
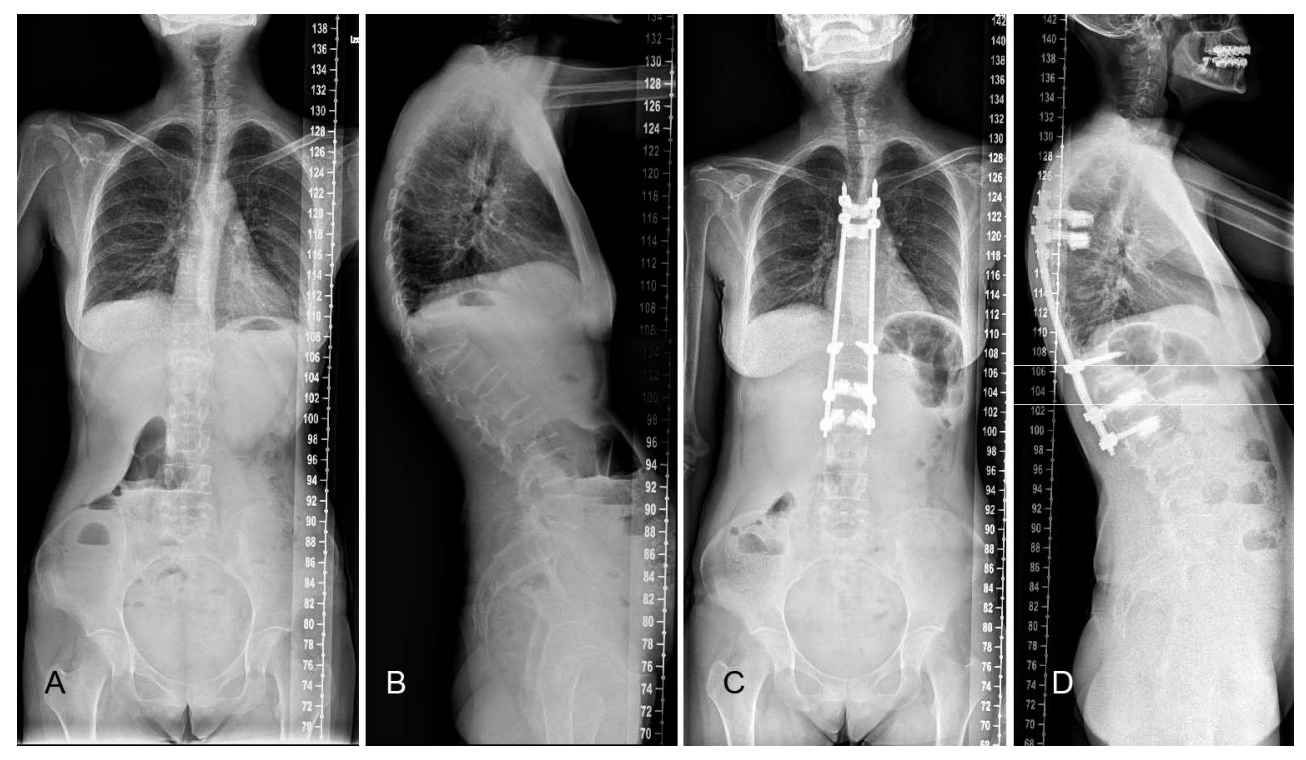

Figure 5. T12 osteotomy. Longer construct with percutaneous screws. 

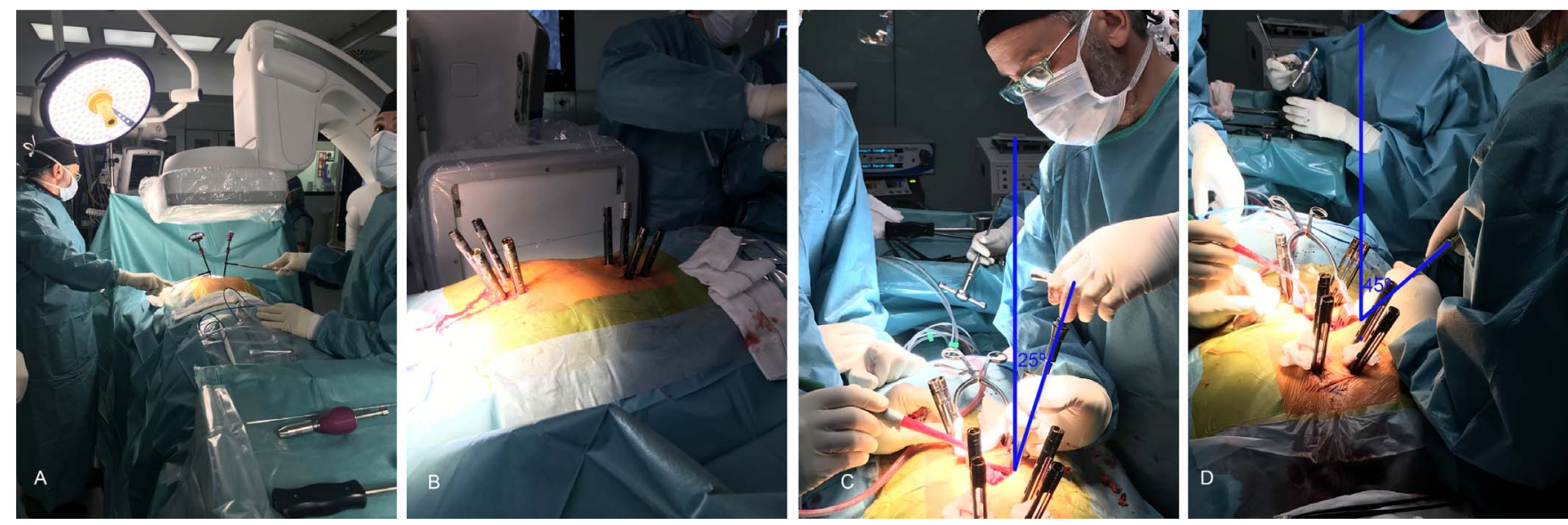

Figure 6. (A, B) Minimally invasive alternative of the technique. (C, D) Inclination of the reamers.

\section{RESULTS}

The osteotomy was performed in 14 patients. Demographic data are summarized in Table 1. All patients were at least American Society of Anesthesiologists II and presented fragile conditions as illustrated by the Charlson index.

As kyphosis is a key factor to decide to perform an osteotomy, correction of kyphosis was one of the most important variables to analyze. The mean preoperative angles were $29.4^{\circ}$ for vertebral kyphosis (range, $45^{\circ}$ to $15^{\circ}$; standard deviation $(\sigma), 10.26$ ) and $38.3^{\circ}$ for regional vertebral kyphosis (range, $17^{\circ}$ to $\left.49^{\circ} ; \sigma, 11.2\right)$. Immediately after the operation, both angles were significantly reduced. Average postoperative vertebral kyphosis was decreased to $0^{\circ}$ (range, $4^{\circ}$ of kyphosis to $3^{\circ}$ of lordosis; $\sigma, 9.3$ ) and postoperative regional vertebral kyphosis to $3.79^{\circ}$ (range from $12^{\circ}$ of kyphosis to $7^{\circ}$ of lordosis; $\sigma$, 14.05). The mean correction angles for vertebral kyphosis and regional kyphosis were $32^{\circ}$ and $39^{\circ}$, respectively (Table 3 ). At final follow-up, kyphosis correction was maintained in all patients. Cement leakage was observed in $10.2 \%$ of cemented vertebrae. According to Yeom's classification, ${ }^{16}$ we found type-B leakage (epidural leakage) in 3.9\%, type-S leakage (lateral venous leakage) in $9.6 \%$, and type-C leakage in 1 vertebra. No cases of discal leakage were identified. No rod fractures or mechanical complications were observed at the level of the osteotomy.

Functional scores highlight an important improvement in the quality of life of the patients after surgery. ODI and VAS scores decreased significantly with a decrease of 33 points in ODI and of 4 points in back VAS. Both results exceed the minimum clinically important difference of $20 \%$ for $\mathrm{ODI}^{17}$ and 2.2 points for VAS. ${ }^{18}$ The 4 patients with neurological deficits improved at least one level on the American Spinal Injury Association scale. The overall patient satisfaction assessed by an enquiry at final follow-up showed a satisfaction rate of $93 \%$.

Table 3. Kyphosis correction.

\begin{tabular}{|c|c|c|c|c|c|c|c|}
\hline Patient no. & Level of the Fracture & Preop VK & Preop RK & Postop VK & Postop RK & Correction VK & Correction RK \\
\hline 1 & L3 & 29 & 34 & -2 & -3 & 31 & 37 \\
\hline 2 & T11 & 40 & 53 & -2 & -3 & 42 & 56 \\
\hline 3 & $\mathrm{~T} 12$ & 25 & 47 & -5 & 15 & 30 & 32 \\
\hline 4 & L1 & 21 & 31 & -3 & -5 & 24 & 36 \\
\hline 5 & L1 & 13 & 26 & -1 & 8 & 14 & 18 \\
\hline 6 & $\mathrm{~T} 12$ & 33 & 45 & 2 & 7 & 31 & 38 \\
\hline 7 & $\mathrm{~T} 12$ & 28 & 30 & 0 & 3 & 28 & 27 \\
\hline 8 & L1 & 26 & 33 & 4 & 12 & 22 & 21 \\
\hline 9 & T12 & 45 & 47 & 3 & 11 & 42 & 36 \\
\hline 10 & $\mathrm{~T} 11$ & 31 & 49 & 2 & 3 & 29 & 46 \\
\hline 11 & L1 & 41 & 45 & 0 & -3 & 41 & 48 \\
\hline 12 & L1 & 29 & 38 & 0 & -3 & 29 & 41 \\
\hline 13 & L1 & 15 & 17 & -3 & -7 & 18 & 24 \\
\hline 14 & $\mathrm{~T} 12$ & 36 & 43 & 4 & 4 & 32 & 39 \\
\hline
\end{tabular}

Abbreviations: Preop, preoperative; Postop, postoperative; RK, regional kyphosis; VK, vertebral kyphosis. 
Table 4. Medical and surgical complications.

\begin{tabular}{ll}
\hline Patient no. & \multicolumn{1}{c}{ Complications } \\
\hline 1 & Postsurgical spinal epidural hematoma \\
2 & None \\
3 & Superficial wound infection \\
4 & None \\
5 & None \\
6 & Proximal junctional kyphosis \\
7 & None \\
8 & None \\
9 & None \\
10 & Pulmonary embolism \\
11 & Pneumothorax \\
12 & Proximal junctional kyphosis \\
13 & None \\
14 & None \\
\hline
\end{tabular}

Mean hospital stay was 15.43 days but presented a large variability (range from 7 to 35 days). Excluding 4 patients with social problems that stayed longer, the mean hospital stay was 9.7 days. The mean loss of blood was $920 \pm 350 \mathrm{~mL}$. Fortythree percent of patients needed a transfusion in the immediate postoperative period. Mean surgical time was 270 minutes (range, 200-350 minutes).

Two medical complications were reported: 1 patient presented with a pulmonary embolism, and another a presented with a pneumothorax. Both conditions were treated successfully during the postoperative period. Surgical complications included 2 PJK that required revision surgery. Patient 6 presented with Parkinson's disease as a comorbidity, and patient 12 had a very short construct. Since this mechanical complication, we have increased the length of the constructs. A postsurgical epidural hematoma and 1 superficial infection of a seroma were also reported. No dural tear or neurological injuries were observed (Table 4).

\section{DISCUSSION}

When it comes to evaluating and treating vertebral fractures, osteoporosis is a game changer. Osteoporosis compression fracture patterns do not fit well in classical classifications like the AO Spine classification for vertebral fractures, and, as a result, specific classifications have been developed. ${ }^{19,20}$ Moreover, as these fractures occur on fragile bones and in frail patients, indications for surgery are not always clear. Although conservative treatment is the first line of treatment, some patients need more aggressive solutions. In the presence of vertebral instability, persistent and intense pain, severe kyphosis, or neurological issues, surgery is recommended.
The objectives of surgery are to stabilize the spine, reduce the kyphosis, decompress the spinal cord when necessary, and avoid reinterventions in frail patients. However, to reach these goals, different strategies and approaches have been described, and controversies on which is the best treatment still exist.

Anterior surgery has been recommended by many authors. $^{8,21}$ Okuda $^{21}$ advocates anterior spinal fusion in patients with osteoporotic vertebral collapse at the thoracolumbar junction with neurological deficits and a unique fracture. Direct decompression of retropulsed bony fragments and reconstruction of a stable anterior column are the main advantages. However, this approach has been related to high comorbidities in elderly patients. ${ }^{22}$ Okuda $^{21}$ also reported the difficulty in maintaining sagittal alignment in osteoporotic patients through anterior-only approaches, insufficient fixation, or postoperative adjacent vertebral collapse. He also stressed the difficulty of salvage surgeries for deep surgical site infection in anterior surgeries.

Posterior and anterior approaches combine the advantages of a strong fixation and a direct anterior decompression. ${ }^{5}$ However, the two approaches significantly increase the surgical time and may need to stage the surgery. As stressed by Kim et $\mathrm{al}^{23}$, long operation time and abdominal or thoracic open surgery are more likely to cause postoperative complications in elderly patients.

For these reasons, our belief is that an all posterior approaches that could restore kyphosis, decompressing the spine and providing a strong fixation would be ideal. This approach has been largely defended for osteoporotic vertebral collapse. ${ }^{10,11,23-25}$ To correct sagittal deformities created by the fractures, osteotomies may be necessary. Their use has been described for sagittal corrections in spinal deformities ${ }^{26}$ but also in the context of osteoporotic fractures. ${ }^{12,27,28}$ Morbidity and complications are high, up to $45 \%,{ }^{28,29}$ and major complications are increased 7 times in patients older than 69 years. $^{30}$

To reduce the morbidity of the surgery in these complex cases, some authors have proposed modifications of the technique of the osteotomies. ${ }^{14,23}$ Kim et $\mathrm{al}^{23}$ performed a wedge osteotomy caudal to the superior endplate of the injured vertebra. According to these authors, this technique has the advantage of preserving the posterior neural arch and provides a bed for fusion. However, Jo at $\mathrm{al}^{14}$ 
performed a transpedicular decancellous procedure creating a wedge resection space toward the intervertebral disk, showing good results in kyphosis correction as well as bony fusion. Both techniques aim at shortening the spine to decrease mechanical and neurological complications.

In this cohort, we have observed that the modifications of the classical decancellation technique presented in our study simplify the osteotomy technique and decrease the risk of neurological injuries as well as blood loss.

Pedicle subtraction osteotomies are normally used in rigid and fixed deformities to correct sagittal malalignment. They are key techniques in "spinal reconstruction surgeries". In highly osteoporotic patients, the low quality of the bone requires us to adapt to a different environment. The underlying principle behind our technique is to shorten the spine by collapsing the posterior wall. It can be understood as the opposite of a reconstruction surgery. We are aiming at exaggerating the defect caused by the fracture and completing the collapse of the vertebra. In many cases, the posterior wall and the pedicles are responsible for the vertebral kyphosis as the anterior column is already collapsed (Figure 1). By completing the collapse of the fracture, we correct the kyphosis.

However, as the sac is not manipulated at any moment of the procedure, we have not reported any neurological injuries or dural tears. In fact, the spinal cord is protected all the time by the medial wall of the pedicle or by the longitudinal posterior ligament, which decreases the risk of injury. Blood loss has also been reduced, probably due to a very limited manipulation of the epidural venous plexus and by compacting the bone during the osteotomy.

Mechanical complications (and more specifically PJK) are frequent complications in patients who underwent vertebral osteotomies. ${ }^{29,31}$ Their etiology is multifactorial. ${ }^{32}$ Potential modifiable risk factors include greater curvature correction and residual sagittal imbalance, and nonmodifiable factors include older age ( $\geq 55$ years old), severe preoperative imbalance, low bone density, presence of comorbidity, and high body mass index. ${ }^{33}$ In our series, we have reported the occurrence of two cases of PJK, 1 in a patient with Parkinson's disease and another in a patient with a very short construct. Both of them underwent revision surgery. To limit the risk of mechanical complications as much as possible, we have designed a different strategy with respect to the length of the instrumentation. Initially, our objective was to implement an instrumentation as short as possible. We have shifted towards longer instrumentation performed with minimally invasive surgical technique, percutaneous screws, and subcutaneous rods (Figure 6). The choice of fusion levels must be carefully planned and is a fundamental part of the surgical planning.

Also, we have generalized the use of cementexpanded screws as they provide a better resistance to pull out, allow for shortening the length of instrumentations, and decrease the risk of screw loosening. Their use is safe and efficient for the treatment of patients with low bone mineral density. ${ }^{34}$ As reported by many authors, ${ }^{34-37}$ the presence of polimethylmethacrylate in the spinal canal is infrequent and, in most of the cases, clinically irrelevant. To reduce the risk of leakages, cementation is realized very slowly, leaving 1 minute between each milliliter of cement. ${ }^{38}$

Finally, in adult deformity surgeries, nonfusion leads to rod fractures at the site of the osteotomy. In the lumbar spine, the use of bone morphogenic protein, allograft, autograft, anterior support, or multirod constructs have been recommended to avoid these complications. In our series, although our technique may not always lead to a solid fusion, no rod fractures at the site of the osteotomy have been observed. In our opinion, in older patients, the complete collapse of the vertebra and the shortening of the spine make the provision of additional support with cages or bone morphogenic protein unnecessary.

\section{Limitations}

Limitations of this study are the relative short case series as well as the short follow-up period.

Moreover, as many of our patients did not tolerate standing position before surgery, preoperative sagittal malalignment was not routinely assessed.

\section{CONCLUSION}

OVFs are complex and challenging fractures. They can lead to severe deformities and produce high morbidity in older and fragile patients. The ideal technique should allow for stabilization of the spine at the fracture site, reduce the kyphosis, and decrease morbidity and revision rates. 
In this article, we have described a simplified technique of pedicle and posterior wall decancellation that helps to correct the kyphosis produced by osteoporotic fractures and decreases the risk of blood loss or neurological injuries.

\section{ACKNOWLEDGMENTS}

We want to express our gratitude to Elena Ludwig for her fantastic illustrations.

\section{REFERENCES}

1. Johnell O, Kanis JA. An estimate of the worldwide prevalence and disability associated with osteoporotic fractures. Osteoporos Int. 2006;17(12):1726-1733. doi:10.1007/s00198006-0172-4

2. Rajasekaran S, Kanna RM, Schnake KJ, et al. Osteoporotic thoracolumbar fractures-how are they different?-Classification and treatment algorithm. J Orthop Trauma. 2017;31(9):S49-S56. doi:10.1097/BOT.0000000000000949

3. Alexandru D. Evaluation and management of vertebral compression fractures. Perm J. 2012;16(4):46-51. doi:10.7812/ TPP/12-037

4. Goldstein CL, Chutkan NB, Choma TJ, Orr RD. Management of the elderly with vertebral compression fractures. Neurosurgery. 2015;77(4):S33-S45. doi:10.1227/NEU. 0000000000000947

5. Park HY, Ahn JH, Ha KY, et al. Clinical and radiologic features of osteoporotic spine fracture with delayed neurologic compromises. World Neurosurg. 2018;120:e1295-e1300. doi:10. 1016/j.wneu. 2018.09.056

6. Spiegl U, Jarvers JS, Heyde CE, Josten C. Osteoporotic vertebral body fractures of the thoracolumbar spine: indications and techniques of a $360^{\circ}$-stabilization. Eur J Trauma Emerg Surg. 2017;43(1):27-33. doi:10.1007/s00068-016-0751-9

7. Guo DQ, Yu M, Zhang SC, et al. Novel surgical strategy for treating osteoporotic vertebral fractures with cord compression. Orthop Surg. 2019;11(6):1082-1092. doi:10.1111/os. 12558

8. Mochida J, Toh E, Chiba M, Nishimura K. Treatment of osteoporotic late collapse of a vertebral body of thoracic and lumbar spine. J Spinal Disord. 2001;14(5):393-398. doi:10.1097/ 00002517-200110000-00004

9. Formica M, Zanirato A, Cavagnaro L, et al. Vertebral body osteonecrosis: proposal of a treatment-oriented classification system. Eur Spine J. 2018;27(Suppl 2):190-197. doi:10. 1007/s00586-018-5600-6

10. Shikata J, Yamamuro T, Iida H, Shimizu K, Yoshikawa J. Surgical treatment for paraplegia resulting from vertebral fractures in senile osteoporosis. Spine (Phila Pa 1976). 1990;15(6):485-489. http://www.ncbi.nlm.nih.gov/pubmed/ 2402688.

11. Ataka H, Tanno T, Yamazaki M. Posterior instrumented fusion without neural decompression for incomplete neurological deficits following vertebral collapse in the osteoporotic thoracolumbar spine. Eur Spine J. 2009;18(1):69-76. doi:10.1007/s00586-008-0821-8

12. Suk SI, Kim JH, Lee SM, Chung ER, Lee JH. Anterior- posterior surgery versus posterior closing wedge osteotomy in posttraumatic kyphosis with neurologic compromised osteoporotic fracture. Spine (Phila Pa 1976). 2003;28(18):2170-2175. doi:10.1097/01.BRS.0000090889.45158.5A

13. Spiegl UJ, Anemüller C, Jarvers JS, von der Höh N, Josten C, Heyde CE. Hybrid stabilization of unstable osteoporotic thoracolumbar vertebral body fractures: clinical and radiological outcome after a mean of 4 years. Eur Spine J. 2019;28(5):(0123456789). doi:10.1007/s00586-019-05957-8

14. Jo DJ, Kim YS, Kim SM, Kim KT, Seo EM. Clinical and radiological outcomes of modified posterior closing wedge osteotomy for the treatment of posttraumatic thoracolumbar kyphosis. J Neurosurg Spine. 2015;23(4):510-517. doi:10.3171 2015.1.SPINE131011

15. Schmoelz W, Heinrichs $\mathrm{CH}$, Schmidt S, et al. Timing of PMMA cement application for pedicle screw augmentation affects screw anchorage. Eur Spine J. 2017;26(11):2883-2890. doi:10.1007/s00586-017-5053-3

16. Yeom JS, Kim WJ, Choy WS, Lee CK, Chang BS, Kang JW. Leakage of cement in percutaneous transpedicular vertebroplasty for painful osteoporotic compression fractures. J Bone Joint Surg B. 2003;85(1):83-89. doi:10.1302/0301-620X. 85B1.13026

17. Schwind J, Learman K, O'Halloran B, Showalter C, Cook C. Different minimally important clinical difference (MCID) scores lead to different clinical prediction rules for the Oswestry disability index for the same sample of patients. $J$ Man Manip Ther. 2013;21(2):71-78. doi:10.1179/2042618613Y. 0000000028

18. Parker SL, Mendenhall SK, Shau DN, et al. Minimum clinically important difference in pain, disability, and quality of life after neural decompression and fusion for same-level recurrent lumbar stenosis: Understanding clinical versus statistical significance- Clinical article. J Neurosurg Spine. 2012;16(5):471-478. doi:10.3171/2012.1.SPINE11842

19. Sugita M, Watanabe N, Mikami Y, Hase H, Kubo T. Classification of vertebral compression fractures in the osteoporotic spine. J Spinal Disord Tech. 2005;18(4):376-381. http:// www.ncbi.nlm.nih.gov/pubmed/16021021.

20. Schnake KJ, Blattert TR, Hahn P, et al. Classification of osteoporotic thoracolumbar spine fractures: recommendations of the spine section of the German Society for Orthopaedics and Trauma (DGOU). Glob Spine J. 2018;8(2 Suppl):46S-49S. doi: $10.1177 / 2192568217717972$

21. Okuda S, Oda T, Yamasaki R, Haku T, Maeno T, Iwasaki M. Surgical outcomes of osteoporotic vertebral collapse: a retrospective study of anterior spinal fusion and pedicle subtraction osteotomy. Glob Spine J. 2012;2(4):221-226. doi:10.1055/s-0032-1331461

22. Mei L, Sang W, Chen Z, et al. Titanium mesh bone grafting combined with pedicle screw internal fixation for treatment of Kummell disease with cord compression: a case report and literature review. Medicine (Baltimore). 2018;97(36). doi:10.1097/MD.0000000000012183

23. Kim S, Chung J, Park Y, Choi S, Seo H. Modified pedicle subtraction osteotomy for osteoporotic vertebral compression fractures. Orthop Surg. 2020;12(2):388-395. doi: $10.1111 /$ os. 12589

24. Patil S, Rawall S, Singh D, et al. Surgical patterns in osteoporotic vertebral compression fractures. Eur Spine J. 2013;22(4):883-891. doi:10.1007/s00586-012-2508-4

25. Shawky A, Kroeber M. Shortening spinal column 
reconstruction through posterior only approach for the treatment of unstable osteoporotic burst lumber fracture: a case report. Arch Orthop Trauma Surg. 2013;133(2):167-169. doi:10.1007/s00402-012-1653-x

26. Schwab F, Blondel B, Chay E, et al. The comprehensive anatomical spinal osteotomy classification. Neurosurgery. 2014;74(1):112-120. doi:10.1227/NEU.0000000000000182o

27. Chang KW, Chen YY, Lin CC, Hsu HL, Pai KC. Apical lordosating osteotomy and minimal segment fixation for the treatment of thoracic or thoracolumbar osteoporotic kyphosis. Spine (Phila Pa 1976). 2005;30(14):1674-1681. doi:10.1097/01. brs.0000170450.77554.bc

28. Kim WJ, Lee ES, Jeon SH, Yalug I. Correction of osteoporotic fracture deformities with global sagittal imbalance. Clin Orthop Relat Res. 2006;443:75-93. doi:10.1097/01. blo.0000200237.22308.93

29. Hyun SJ, Rhim SC. Clinical outcomes and complications after pedicle subtraction osteotomy for fixed sagittal imbalance patients: a long-term follow-up data. J Korean Neurosurg Soc. 2010;47(2):95-101. doi:10.3340/jkns.2010.47.2.95

30. Drazin D, Shirzadi A, Rosner J, et al. Complications and outcomes after spinal deformity surgery in the elderly: review of the existing literature and future directions. Neurosurg Focus. 2011;31(4):E3. doi:10.3171/2011.7.FOCUS11145

31. Barrey C, Perrin G, Michel F, Vital JM, Obeid I. Pedicle subtraction osteotomy in the lumbar spine: indications, technical aspects, results and complications. Eur J Orthop Surg Traumatol. 2014;24(Suppl 1). doi:10.1007/s00590-014-1470-8

32. Sebaaly A, Sylvestre C, El Quehtani Y, et al. Incidence and risk factors for proximal junctional kyphosis: results of a multicentric study of adult scoliosis. Clin Spine Surg. 2018;31(3):E178-E183. doi:10.1097/BSD.0000000000000630

33. Nguyen NLM, Kong CY, Hart RA. Proximal junctional kyphosis and failure - diagnosis, prevention, and treatment. Curr Rev Musculoskelet Med. 2016;9(3):299-308. doi:10.1007/ s12178-016-9353-8

34. Martín-Fernández M, López-Herradón A, Piñera AR, et al. Potential risks of using cement-augmented screws for spinal fusion in patients with low bone quality. Spine $J$. 2017;17(8):1192-1199. doi:10.1016/j.spinee.2017.04.029

35. Álvarez L, Alcaraz M, Pérez-Higueras A, et al. Percutaneous vertebroplasty: functional improvement in patients with osteoporotic compression fractures. Spine (Phila Pa
1976). 2006;31(10):1113-1118. doi:10.1097/01.brs.0000216487. 97965.38

36. Piñera AR, Duran C, Lopez B, Saez I, Correia E, Alvarez L. Instrumented lumbar arthrodesis in elderly patients: prospective study using cannulated cemented pedicle screw instrumentation. Eur Spine J. 2011;20 Suppl 3(2):408-414. doi:10.1007/s00586-011-1907-2

37. Alvarez-Galovich L, Tome-Bermejo F, Moya AB, et al. Safety and efficacy with augmented second-generation perforated pedicle screws in treating degenerative spine disease in elderly population. Int J Spine Surg. 2020;14(5):811-817. doi: $10.14444 / 7115$

38. Hoppe S, Wangler S, Aghayev E, Gantenbein B, Boger A, Benneker LM. Reduction of cement leakage by sequential PMMA application in a vertebroplasty model. Eur Spine J. 2016;25(11):3450-3455. doi:10.1007/s00586-015-3920-3

Disclosures and COI: This study has not received any financial support. The following are relationships of the authors with organizations and entities (none are related to the present manuscript): Dr Nicolas Plais is a consultant for Medtronic and reports stocks in Nuvasive and Spinewave, Dr Alvarez Galovich is a consultant for Nuvasive, Spineart, and Zimmer-Biomet, and Dr Peiro-Garcia is a consultant for Spineart and Stryker. For the remaining authors, no conflicts of interest were declared.

Corresponding Author: Nicolas Plais, MD, Paseo del Agua, 15, Parque del Cubillas, 18220 Albolote, Spain. Phone: (+34) 670-9604790; Email: nicolas.plais@me.com.

Published 0 Month 2021

This manuscript is generously published free of charge by ISASS, the International Society for the Advancement of Spine Surgery. Copyright (c) 2021 ISASS. To see more or order reprints or permissions, see http://ijssurgery.com. 